\title{
The partial femoral condyle focal resurfacing (HemiCAP-UniCAP) for treatment of full-thickness cartilage defects, systematic review and meta-analysis
}

\author{
Hany Elbardesy, Matthew Nagle, Lydia Simmons, James Harty
}

From the Cork University Hospital, Ireland

Knee osteochondral defects are a common problem among people, especially young and active patients. So effective joint preserving surgeries is essential to prevent or even delay the onset of osteoarthritis for these group of patients. This study aims to critically appraise and evaluate the evidence for the results and effectiveness of femoral condyle resurfacing (HemiCAP/ UniCAP) in treatment of patients with focal femoral condyle cartilage defect.

Using the search terms : HemiCAP, UniCAP, Episurf, focal, femoral, condyle, inlay and resur-facing, we reviewed the PubMed and EMBASE and the Cochrane Database of Systematic Reviews (CDSR) to find any articles published up to March 2020.

The short term follow-up of the HemiCAP shows (6.74 \%) revision rate. However, $29.13 \%$ loss of follow up let us consider these results with caution especially if the revision rate progressively increased with time to $\mathbf{1 9 . 3}$ $\%$ in 5-7 years with no enough evidence for the long term results except the data from the Australian Joint Registry 2018, where the cumulative revision rate was $40.6 \%(33.5,48.4)$ at ten years. The UniCAP that used for defect more than $4 \mathrm{~cm}^{2}$ has a high revision rate $(53.66 \%)$ which is considered unacceptable revision rate in com-parison to another similar prosthesis such as Uni-Knee Arthroplasty (UKA).

The evidence from published studies and our metaanalysis suggests that partial resurfacing of the femoral condyle (HemiCAP) doesn't support its usage as a tool to treat the focal cartilage defect in middleaged patients.

The UniCAP as femoral condyle resurfacing has very high revision rate at 5-7 years $(53.66 \%)$ which make us recommend against its usage.
Keywords : knee focal metallic implant; HemiCAP ; UniCAP ; Wave prosthesis ; inlay design.

\section{INTRODUCTION}

Recently, the number of revision total knee replacement (TKR) is continuously increasing (1). there are expectations of increasing the number of the primary TKR in the next two decades (2), so, it is critical to delay the onset joint replacement surgeries and preserve healthy articular surfaces and bone stock (3). Focal article defect of the femoral condyle of the knee is commonly associated with symptomatic knee $(4,5)$, and more common in patients over forty years old $(6,7)$, which if left untreated it will progress to knee osteoarthritis (OA) (8-10).

There are many different methods to treat knee articular cartilage defects $(11,12)$, however, the age

- Hany Elbardesy, MSc, MRCS, FRCS (Tr\&Orth), FEBOT, SICOT Diploma

- Matthew Nagle, Orthopaedic speciality registrar, MB MSc, FRCS (Tr\&Orth),

- Lydia Simmons, Orthopaedic Senior house officer,

- James Harty, Professor, MSc, FRCS (Tr\&Orth). Cork University Hospital, Cork, Ireland.

Correspondence : Hany Elbardesy, Cork University Hospital, Tel :+353214922000, Fax +3532103437890,

Email : hany.elbardesy@hse.ie

- 2021, Acta Orthopædica Belgica. 
of the patient, site and size of the defect are essential factors before taking the treatment plan (31).

Biological repair methods such as microfractures, autologous chondrocyte implantation (ACI) can be used with good clinical outcome (13-18), but its effectiveness decrease with increase of age to be less effective for patients older than 40 years $(18,19)$.

Total knee replacement in young patients is associated with early failure with wear and loosening due to hyper activities in comparisons to older patients $(20,21)$. So, revision surgeries are more likely before the normally expected life span (15-20 years) of primary knee arthroplasty (22-26).

The partial femoral condyle resurfacing is a surgical option between the biological cartilage reserving surgeries and knee arthroplasty in patients between 40-60 years old with full-thickness cartilage defects (27).

Focal femoral condyle resurfacing (HemiCAP) was introduced in the USA for the first time in 2003, was being used for both femoral condyle and trochlear osteochondral defect or after failed biological cartilage graft for defects less than $4 \mathrm{~cm}^{2}$ and UniCAP for lesion more than $4 \mathrm{~cm}^{2}$ (3,28-32).

The current evidence to date for the use of femoral condyle resurfacing is inconsistent with many studies involving small participant numbers or low follow-up rates. To date, there has not been a systematic review and meta-analysis to accurately assess if the use of HemiCAP and UniCAP in patients with femoral osteochondral defects are associated with better outcomes and a reduced need for further surgeries. We, therefore, aimed to carry out a systematic review and meta-analysis of the current literature to assess the effectiveness of femoral condyle resurfacing in the treatment of patients with focal femoral condyle cartilage defects.

\section{MATERIALS AND METHODS}

A systematic review and meta-analysis were conducted according to Preferred Reporting Items for Systematic reviews and Meta-Analyses (PRISMA) guidelines. Our inclusion criteria were any study about the HemiCAP/UniCAP or focal femoral condyle resurfacing prosthesis with

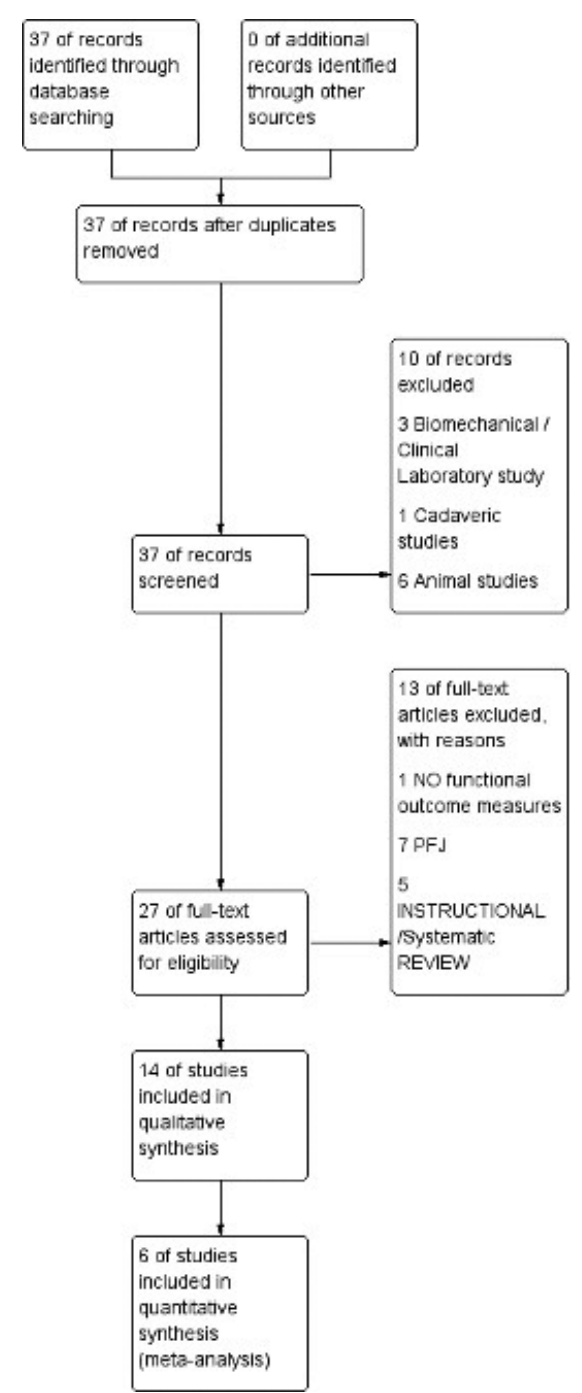

Figure 1. - PRISMA Study flow diagram, PFJ (Patello femoral Joint)

recorded follow-up not less than two years and published until March 2020, the quality of the evidence was classified using the US Preventive Services Task Force system for ranking the level of evidence. Descriptive statistics and methodological quality were calculated for each study.

The first stage we initially assessed only the titles and abstracts of the search result. The second stage involved a careful review of the full-text publications.

We conducted a systematic review and metaanalysis according to Preferred Reporting Items for Systematic reviews and Meta-Analyses (PRISMA) 
guidelines (Figure 1), we conducted the search using the MEDLINE/PubMed, EMBASE and the Cochrane Database of Systematic Reviews (CDSR). These databases were searched for the terms HemiCAP/UniCAP knee implant and knee focal metallic implant. Backward chaining of the reference lists from the retrieved papers was also undertaken to maximise the search. The first step was the initial assessment of only the titles and abstracts of the search results. Followed by the second step by careful review of the full-text publications, the difference between reviewers were reviewed by the third reviewer $(\mathrm{JH})$ until an agreement was achieved.

Our inclusion criteria were any clinical trials involving HemiCAP, UniCAP or focal resurfacing implant with mean follow-up at least two years.

We excluded all cadaveric, biomechanical studies and studies about partial resurfacing of the patellofemoral joint (PFJ). Three studies $(27,30,31)$ were excluded from the meta-analysis as they used outcome measures (HSS, KSS and SF-12 subdomain scores respectively) didn't commonly been used in other studies. Additionally (30,33), used the KOOS score as an outcome measure, but didn't have any pre-operative KOOS data, another study (34) used KOOS score but the only quality of life component was reported. Another two studies $(35,36)$ have been excluded due to using UniCAP prothesis for defects larger than $4 \mathrm{~cm}^{2}$, that not used by other studies and one study (37) been excluded as his study was on two patients only and the same author published another earlier study (3). He didn't mention that those two patients were not included in the previous study. We ranked the level of evidence according to the US Preventive Services Task Force system.

From our included studies we extracted the following: study ID (author, publication year, journal) participants (total number of subjects, mean preoperative age, gender, body mass index (BMI) duration of symptoms. If the study has inclusion/ exclusion criteria or not, (defect site, size, type of prothesis, classification and aetiology), follow-up period, loss of follow up and sources of funding.

The risk of bias (figure 2) for included studies was assessed using the Cochrane risk of bias criteria (38).

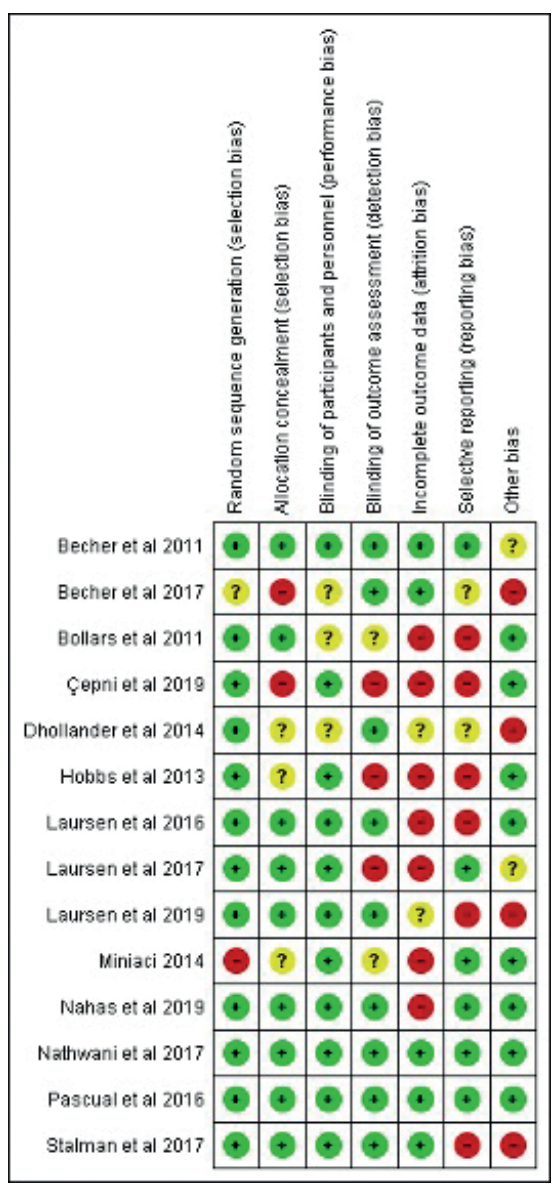

Figure 2. - Risk of bias summary: review authors' judgements about each risk of bias item for each included study( the green colour means low risk of bias the red means high risk of bias and the yellow stands for unclear risk of bias).

Four reviewers (HE, MN, JH and LS) independently cross-checked the risk of bias for included studies, disagreements were resolved through discussion. We extracted the following from included studies: Level of evidence, name of the journal, the total number of subjects, mean followup period, demographics, duration of symptoms, results ( primary and secondary outcome measures, effect size, statistical significance, adverse effects), prior cartilage procedures, concomitant operation/s, defect (classification, aetiology, size, site), and funding.

Based on pre and post-operative changes, we computed mean differences (MD) with 95\% CI discontinuous outcomes, using standard meta-analysis software (RevMan 5.3) (38). 
We used standardised mean differences (SMD) instead of MD to compute effect measures and we used the random-effects model for meta-analyses (39). Evaluation of the risk of bias in included studies was done by (HE) and reviewed again by the other co-authors, One reviewer (HE) entered data into RevMan 5 software for statistical pooling, while the other three reviewers (JH, LS and MN) independently cross-checked data entry.

We planned to do subgroup analyses by evaluating the five components of the KOOS score (pain, symptoms, activities of daily living (ADL), quality of life(Qol) and sport \& recreational activities).

We checked the heterogeneity using the $\mathrm{I}^{2}$ statistic; values of $25 \%$ and less indicated low statistical heterogeneity. The results were presented in a Forrest plot of comparison between the preoperative and postoperative scores.

Our electronic searches returned 37abstracts we excluded three Biomechanical / Clinical Laboratory study (40-42), and one cadaveric study (20), six animal studies (43-48), five instructional/systematic reviews (49-53), seven partial resurfacing of the PFJ (29,54$59)$, and one study that has no functional outcome measures (60). Furthermore, eight studies $(27,30,31,33-$ 37) were included in the systematic review but were excluded from the meta-analysis because they didn't use the KOOS score as an outcome measure. The details of the included studies are demonstrated in Tables 1,2 and 3.

\section{RESULTS}

Fourteen studies on 464 patients( no bilateral cases), 116 males, 193 females, four studies(155 patients) didn't mention the gender $(3,33,61,62)$, the mean age was 47.9 years; the mean BMI was 27.8 ( two studies didn't mention the BMI $(32,63)$, one study indicated that all BMI was more than 30(64), another claimed that was less than 35 (65), one mentioned the weight by the kilogram, the mean was $63 \mathrm{~kg}(30)$.

All studies were level IV evidence except one(27), which was level III.

We did a meta-analysis of KOOS score (figure 3) for six prospective cohort studies (3,32,6163,65). We compared between the preoperative

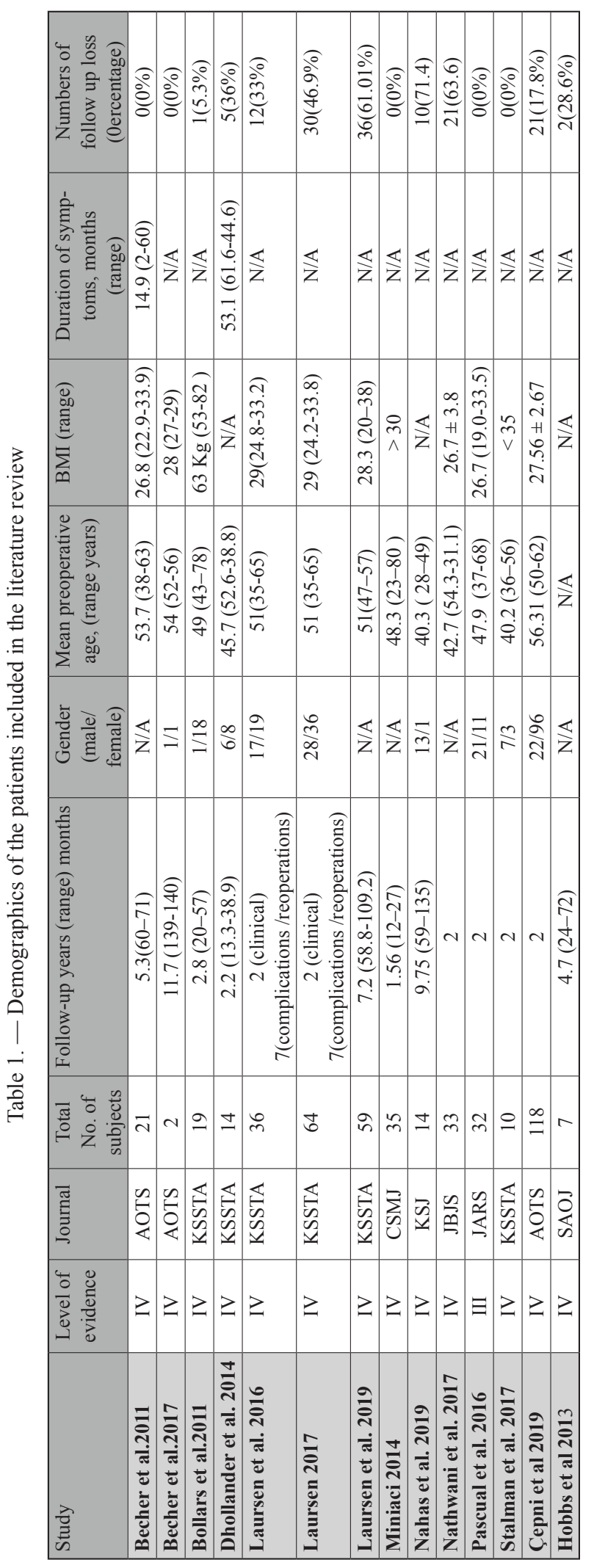




\begin{tabular}{|c|c|c|c|c|c|c|c|c|c|c|c|c|c|c|}
\hline 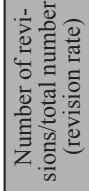 & $\begin{array}{l}\text { a } \\
\text { in } \\
o \\
\frac{a}{2} \\
\text { a }\end{array}$ & $\begin{array}{l}0 \\
0 \\
0 \\
0 \\
0\end{array}$ & $\begin{array}{l}\text { 递 } \\
\text { aे }\end{array}$ & 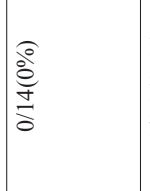 & 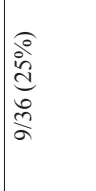 & 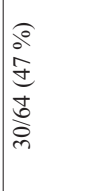 & 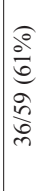 & 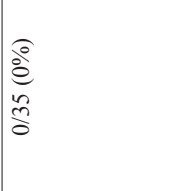 & 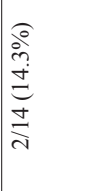 & 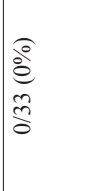 & 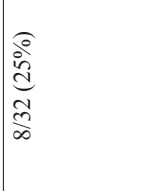 & $\begin{array}{l}\frac{0}{0} \\
\stackrel{0}{\circ} \\
\stackrel{0}{0}\end{array}$ & 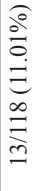 & 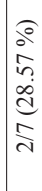 \\
\hline 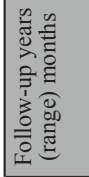 & 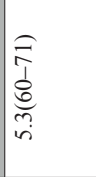 & 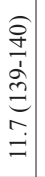 & 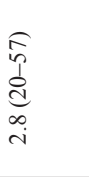 & 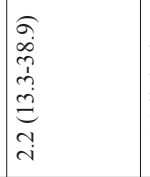 & 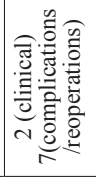 & 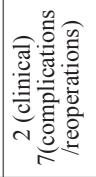 & 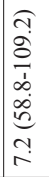 & 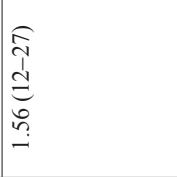 & 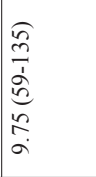 & N & N & $\sim$ & $\alpha$ & 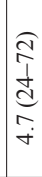 \\
\hline 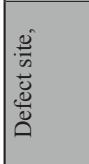 & U & $\mathbb{z}$ & 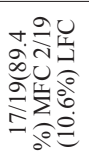 & 崩 & $\overleftrightarrow{\mathrm{z}}$ & $\overleftrightarrow{\underline{z}}$ & $\overleftrightarrow{⿱ 亠 乂}$ & 茂 & 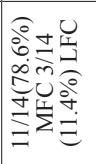 & 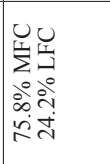 & $\overleftrightarrow{\widehat{z}}$ & $\sum$ &  & 芒 \\
\hline 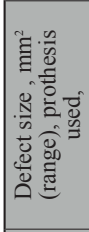 & 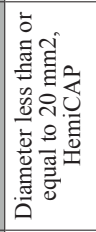 & 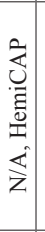 & 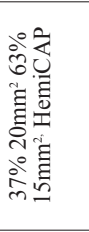 & 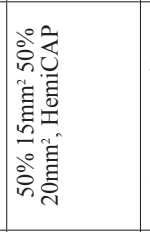 & 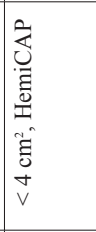 & 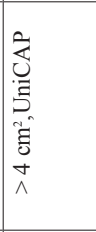 & 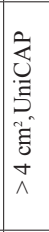 & 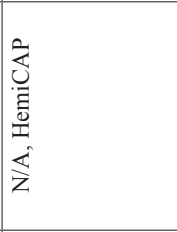 & 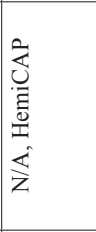 & 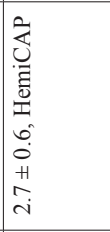 & 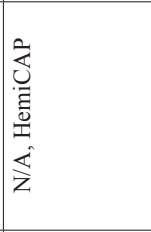 & 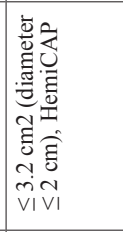 & 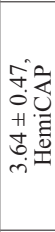 & 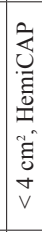 \\
\hline 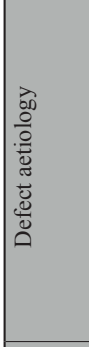 & $\overleftrightarrow{z}$ & $\frac{k}{z}$ & 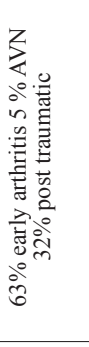 & 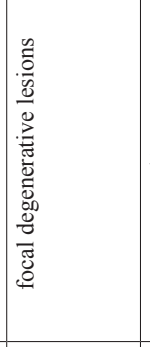 & $\overleftrightarrow{z}$ & $\mathbb{z}$ & $\overleftrightarrow{z}$ & $\overleftrightarrow{z}$ & $\frac{\mathbb{a}}{z}$ & 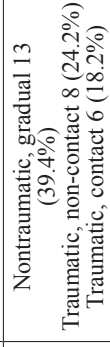 & $\overleftrightarrow{z}$ & $\overleftrightarrow{z}$ & $\overleftrightarrow{z}$ & $\overleftrightarrow{\mathrm{z}}$ \\
\hline 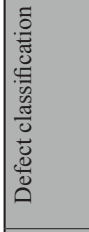 & 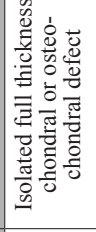 & $\mathbb{z}$ & & 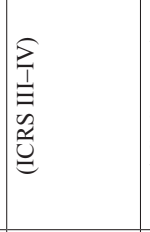 & 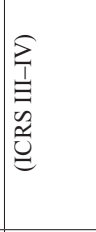 & 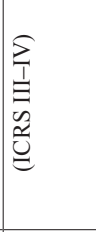 & 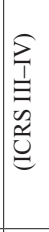 & 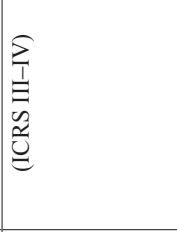 & $\frac{\mathbb{a}}{z}$ & $\mathbb{a}$ & $\overleftrightarrow{\Delta}$ & 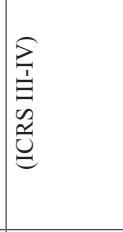 & 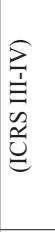 & 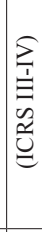 \\
\hline 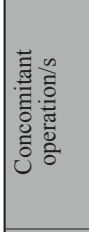 & $\overleftrightarrow{z}$ & $\mathbb{z}$ & 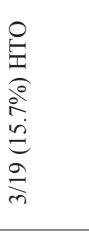 & 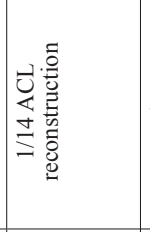 & $\overleftrightarrow{z}$ & $\mid \overleftarrow{z}$ & $\overleftrightarrow{\mathbb{Z}}$ & 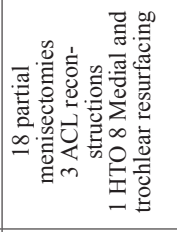 & \begin{tabular}{|l}
$\vec{U}$ \\
$\mathbb{I}$
\end{tabular} & 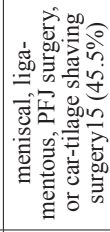 & $\frac{\Delta}{z}$ & $\overleftrightarrow{z}$ & $\overleftrightarrow{z}$ & $\overleftrightarrow{\mathrm{z}}$ \\
\hline 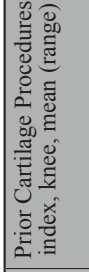 & $\begin{array}{l}\hat{T} \\
\hat{d} \\
u \\
o \\
-1\end{array}$ & $\mathbb{z}$ & そ &  & $\overleftrightarrow{\mathrm{z}}$ & $\overleftrightarrow{\underline{z}}$ & $\overleftrightarrow{\mathrm{Z}}$ & 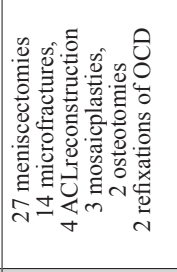 & $\overleftrightarrow{z}$ & 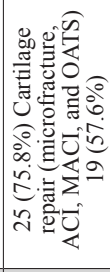 & 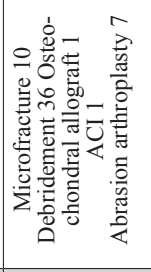 & 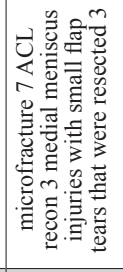 & $\vec{\lambda}$ & $\overleftrightarrow{z}$ \\
\hline 密 & 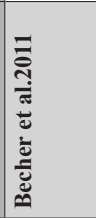 & 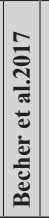 & 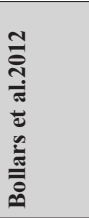 & 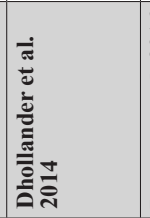 & 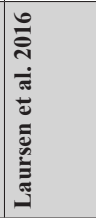 & 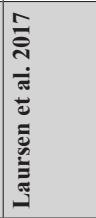 & 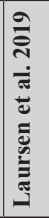 & 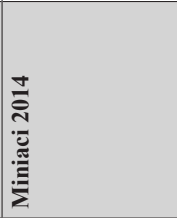 & 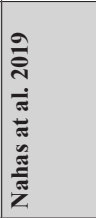 & 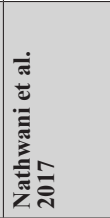 & 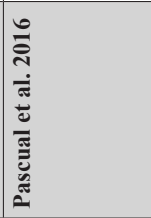 & 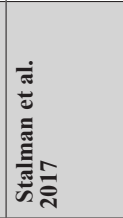 & 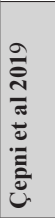 & 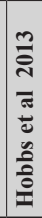 \\
\hline
\end{tabular}


Table 3. - Studies outcome scores

\begin{tabular}{|l|l|}
\hline Study & Outcome score \\
\hline Becher et al.2011 & KOOS, SF-36, Tagner activity level \\
\hline Becher et al.2017 & KOOS, Tagner activity level \\
\hline Bollars et al.2012 & KOOS, HSS, IKDC evaluation \\
\hline Dhollander et al. 2014 & KOOS \\
\hline Laursen et al. 2016 & KSS \\
\hline Laursen et al. 2017 & KSS \\
\hline Laursen et al. 2019 & KSS \\
\hline Miniaci 2014 & $\begin{array}{l}\text { KOOS, VAS pain, SF-36, Tagner activity } \\
\text { level }\end{array}$ \\
\hline Nahas at al. 2019 & KOOS, \\
\hline Nathwani et al. 2017 & KOOS, VAS pain, Tagner activity level \\
\hline Pascual et al. 2016 & WOMAC,SF-12 \\
\hline Stalman et al. 2017 & KOOS, VAS pain,EQ5D \\
\hline Çepni et al 2019 & KOOS, VAS pain, Tagner activity level \\
\hline Hobbs et al 2013 & KOOS, IKDC evaluation \\
\hline
\end{tabular}

and post-operative KOOS score at two years. The preoperative number of patients was 127 ; the postoperative was $90(70.87 \%)$ with $29.13 \%$ loss of follow up. The Standard Mean Difference for pain was 5.61 (3.11-8.11), symptoms 4.96 (2.63-7.28), -ADL 5.08(2.76-7.40), Sport\&Rec 4.35 (1.61-7.09) and QOL 5 (2.51-7.49). Test for overall effect: Z $=9,62(\mathrm{P}<0.0001)$, test for subgroup differences $\mathrm{Chi}^{2}=0.45, \mathrm{df}=4(\mathrm{P}=0.98), \mathrm{I}^{2} 0 \%$ (low heterogeneity).

A total number of 464 patients recruited from fourteen studies were included in the systematic review. There was a significant improvement in all outcomes scores $(\mathrm{P}<0.001)$ in two years follow up for eight studies $(n=268)$; however, the revision rate was $6.74 \%$. In medium-term follow up (5-7 years)

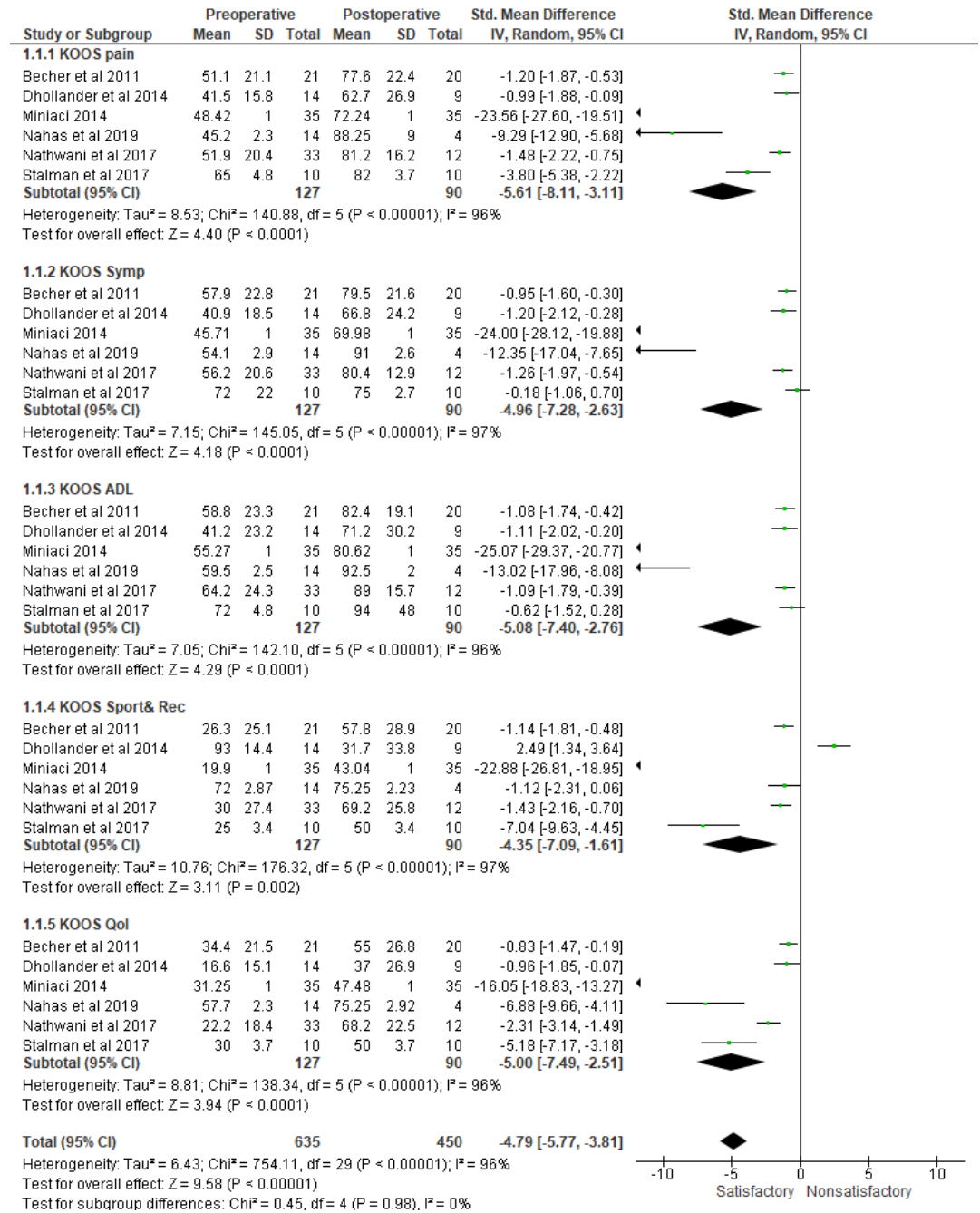

Figure 3. - Forest plot of KOOS score. 
in two studies $(\mathrm{n}=47)$ the revision rate was $19.3 \%$, no enough data to evaluate the long term follow up as only two studies $(\mathrm{n}=16)$ which have long term follow up period (10-12 years) the revision rate was $12.5 \%$.

The five years revision rate for UniCAP (which is used for large chondral size more than $4 \mathrm{~cm}^{2}$ ) is $53.66 \%$.

\section{DISCUSSION}

In comparison between the preoperative and post-operative KOOS score in the meta-analysis, there was an improvement in all components of the score. However, the KOOS mean change values in patients with knee OA varies with intervention and increased with length of follow-up (66), so, that degree of improvement in our meta-analysis doesn't reflect the success of the HemiCAP. Additionally, $(29.13 \%)$ loss of follow up let us consider these results with caution.

For short term follow up ( 2 years) the revision rate is $(6.74 \%)$ among 341 patients got HemiCAP. $(27,30,32-34,61,62,65)$, in comparison with other evidence with a larger volume of patients such as The Australian Joint Registry 2018 that reported $16.6 \%(12.2-22.3)$ revision rate at two years which is almost 2.5 times the revision rate in our review which raise the concern of publication bias of the included studies that have low level of evidence.

For medium-term follow (5-7 years), the revision rate was $19.3 \%(3,36)$, which is also less than the revision rate of the Australian Joint Registry 2018 which was $27.7 \%(22.0,34.6)$ at five years and both values is considered high if we compare it to the revision rate of the UKA which is 8.3 (7.2, 9.6). (67) that makes the UKA is better option with stronger evidence to support its usage.

No enough date for long term results of the HemiCAP. However, the limited number of studies in literatures showed revision rate $(12.5 \%$, ) at 9.4 years $(37,63)$ but the proportion of loss of follow up was $62.5 \%$ which doesn't give this figures any weight. In the Australian Joint Registry 2018 (67), the cumulative revision rate was $40.6 \%(33.5,48.4)$ at ten years which is considered high.

For larger defect more than or equal to $4 \mathrm{~cm}^{2}$, the UniCAP was used however the revision rate for UniCAP is $53.66 \%(35,36)$ which is consider unacceptable revision rate in comparison to another similar prosthesis such as UKA while its revision rate in five and ten years is $8.0 \%(7.8,8.3)$ and 14.6 $\%(14.3,15.0)$ respectively (67), even the revision rate in seventeen years for the UKA is $25.7 \%$ (24.5, 26.9) (67), which is less than half of the revision rate for UniCAP after 5-7 years only.

We couldn't find any data about the UniCAP for the femoral condyle in any National joint registry which means that it is not popular among orthopaedic surgeons, the result of these two studies, $(35,36)$ with reported high revision rate justifies the unpopularity of this kind of prosthesis.

\section{Acknowledgements}

We thank Julianne O'Callaghan, Library Assistant| of the South Infirmary Victoria university hospital Libraries for her help with conducting electronic searches.

\section{Contributions of authors}

HE was involved with data extraction, data analysis and interpretation, and drafting of the review, JH, MN and LS took responsibility for the integrity of the work as a whole, from inception to finished article.

\section{REFERENCES}

1. Bozic KJ, Kurtz SM, Lau E, Ong K, Chiu V, Vail TP, et al. The epidemiology of revision total knee arthroplasty in the United States. Clin Orthop Relat Res [Internet]. 2010 Jan ; 468(1) : 45-51. Available from : http://www.ncbi.nlm. nih.gov/pubmed/19554385

2. Kurtz S, Ong K, Lau E, Mowat F, Halpern M. Projections of primary and revision hip and knee arthroplasty in the United States from 2005 to 2030. J Bone Joint Surg Am [Internet]. 2007 Apr ; 89(4) : 780-5. Available from : http:// www.ncbi.nlm.nih.gov/pubmed/17403800

3. Becher C, Kalbe C, Thermann H, Paessler HH, Laprell H, Kaiser T, et al. Minimum 5-year results of focal articular prosthetic resurfacing for the treatment of fullthickness articular cartilage defects in the knee. Arch. Orthop. Trauma Surg. $2011 ; 131(8)$ : 1135-43.

4. Davies-Tuck ML, Wluka AE, Wang Y, Teichtahl AJ, Jones G, Ding C, et al. The natural history of cartilage defects in people with knee osteoarthritis. Osteoarthr Cartil [Internet]. 2008 Mar; 16(3): 337-42. Available from: http://www.ncbi.nlm.nih.gov/pubmed/17698376

5. Wluka AE, Ding C, Jones G, Cicuttini FM. The clinical correlates of articular cartilage defects in symptomatic knee 
osteoarthritis : a prospective study. Rheumatology (Oxford) [Internet]. 2005 Oct ; 44(10) : 1311-6. Available from : http://www.ncbi.nlm.nih.gov/pubmed/16030084

6. Curl WW, Krome J, Gordon ES, Rushing J, Smith BP, Poehling GG. Cartilage injuries : a review of 31,516 knee arthroscopies. Arthroscopy [Internet]. 1997 Aug ; 13(4) : 456-60. Available from: http://www.ncbi.nlm.nih.gov/ pubmed/9276052

7. Hjelle K, Solheim E, Strand T, Muri R, Brittberg M. Articular cartilage defects in 1,000 knee arthroscopies. Arthroscopy [Internet]. 2002 Sep ; 18(7):730-4. Available from: http://www.ncbi.nlm.nih.gov/pubmed/12209430

8. Cicuttini F, Ding C, Wluka A, Davis S, Ebeling PR, Jones G. Association of cartilage defects with loss of knee cartilage in healthy, middle-age adults : a prospective study. Arthritis Rheum [Internet]. 2005 Jul ; 52(7) : 2033-9. Available from: http://www.ncbi.nlm.nih.gov/ pubmed/15986359

9. Jackson DW, Lalor PA, Aberman HM, Simon TM. Spontaneous repair of full-thickness defects of articular cartilage in a goat model. A preliminary study. J Bone Joint Surg Am [Internet]. 2001 Jan; 83(1) : 53-64. Available from : http://www.ncbi.nlm.nih.gov/pubmed/11205859

10. Wang Y, Ding C, Wluka AE, Davis S, Ebeling PR, Jones $\mathbf{G}$, et al. Factors affecting progression of knee cartilage defects in normal subjects over 2 years. Rheumatology (Oxford) [Internet]. 2006 Jan ; 45(1) : 79-84. Available from : http://www.ncbi.nlm.nih.gov/pubmed/16188947

11. Niemeyer P, Feucht MJ, Fritz J, Albrecht D, Spahn G, Angele P. Cartilage repair surgery for full-thickness defects of the knee in Germany : indications and epidemiological data from the German Cartilage Registry (KnorpelRegister DGOU). Arch Orthop Trauma Surg [Internet]. 2016 Jul ; 136(7) : 891-7. Available from : http://www.ncbi.nlm.nih. gov/pubmed/27062375

12. Spahn G, Fritz J, Albrecht D, Hofmann GO, Niemeyer P. Characteristics and associated factors of Klee cartilage lesions : preliminary baseline-data of more than 1000 patients from the German cartilage registry (KnorpelRegister DGOU). Arch Orthop Trauma Surg [Internet]. 2016 Jun $21 ; 136(6)$ : 805-10. Available from : http://link.springer.com/10.1007/s00402-016-2432-x

13. Hangody L, Füles P. Autologous osteochondral mosaicplasty for the treatment of full-thickness defects of weightbearing joints. $J$ Bone $J t$ Surgery-American Vol [Internet]. 2003 ; 85 : 25-32. Available from: https://insights.ovid. com/crossref?an=00004623-200300002-00004

14. Brittberg M, Lindahl A, Nilsson A, Ohlsson C, Isaksson O, Peterson L. Treatment of deep cartilage defects in the knee with autologous chondrocyte transplantation. $N$ Engl $J$ Med [Internet]. 1994 Oct 6 ; 331(14) : 889-95. Available from : http://www.ncbi.nlm.nih.gov/pubmed/8078550

15. Beck JJ, Sugimoto D, Micheli L. Sustained Results in Long-Term Follow-Up of Autologous Chondrocyte Implantation (ACI) for Distal Femur Juvenile Osteochondritis Dissecans (JOCD). Adv Orthop [Internet]. 2018 ;
2018 : 7912975. Available from : http://www.ncbi.nlm.nih. gov/pubmed/30345118

16. Browne JE, Anderson AF, Arciero R, Mandelbaum B, Moseley JB, Micheli LJ, et al. Clinical outcome of autologous chondrocyte implantation at 5 years in US subjects. Clin Orthop Relat Res [Internet]. 2005 Jul; (436) : 237-45. Available from : http://www.ncbi.nlm.nih. gov/pubmed/15995447

17. Berruto M, Ferrua P, Pasqualotto S, Uboldi F, Maione A, Tradati D, et al. Long-term follow-up evaluation of autologous chondrocyte implantation for symptomatic cartilage lesions of the knee : A single-centre prospective study. Injury [Internet]. 2017 Oct ; 48(10) : 2230-4. Available from: http:/www.ncbi.nlm.nih.gov/ pubmed/28803652

18. Pareek A, Carey JL, Reardon PJ, Peterson L, Stuart MJ, Krych AJ. Long-Term Outcomes after Autologous Chondrocyte Implantation : A Systematic Review at Mean Follow-Up of 11.4 Years. Cartilage [Internet]. 2016 Oct; 7(4) : 298-308. Available from : http://www.ncbi.nlm.nih. gov/pubmed/27688838

19. Steadman JR, Briggs KK, Rodrigo JJ, Kocher MS, Gill TJ, Rodkey WG. Outcomes of microfracture for traumatic chondral defects of the knee : average 11-year follow-up. Arthroscopy [Internet]. 19(5) : 477-84. Available from : http:/www.ncbi.nlm.nih.gov/pubmed/12724676

20. Becher C, Huber R, Thermann H, Paessler HH, Skrbensky G. Effects of a contoured articular prosthetic device on tibiofemoral peak contact pressure: A biomechanical study. Knee Surgery, Sport Traumatol. Arthrosc. 2008 ; 16(1) : 56-63.

21. Kooijman HJ, Driessen APPM, van Horn JR. Longterm results of patellofemoral arthroplasty. A report of 56 arthroplasties with 17 years of follow-up. J Bone Joint Surg $\mathrm{Br}$ [Internet]. $2003 \mathrm{Aug} ; 85(6)$ : 836-40. Available from : http:/www.ncbi.nlm.nih.gov/pubmed/12931801

22. Ranawat CS, Flynn WF, Saddler S, Hansraj KK, Maynard MJ. Long-term results of the total condylar knee arthroplasty. A 15-year survivorship study. Clin Orthop Relat Res [Internet]. 1993 Jan; (286) : 94-102. Available from : http://www.ncbi.nlm.nih.gov/pubmed/8425373

23. Crowder AR, Duffy GP, Trousdale RT. Long-term results of total knee arthroplasty in young patients with rheumatoid arthritis. J Arthroplasty [Internet]. 2005 Oct ; 20(7 Suppl 3) : 12-6. Available from : http://www.ncbi.nlm.nih.gov/ pubmed/16213997

24. Kurtz SM, Lau E, Ong K, Zhao K, Kelly M, Bozic KJ. Future young patient demand for primary and revision joint replacement : national projections from 2010 to 2030. Clin Orthop Relat Res [Internet]. 2009 Oct; 467(10) : 2606-12. Available from: http://www.ncbi.nlm.nih.gov/ pubmed/19360453

25. Rand JA, Ilstrup DM. Survivorship analysis of total knee arthroplasty. Cumulative rates of survival of 9200 total knee arthroplasties. J Bone Joint Surg Am [Internet]. 1991 Mar ; 73(3) : 397-409. Available from : http://www.ncbi. nlm.nih.gov/pubmed/2002078 
26. Delanois RE, Mistry JB, Gwam CU, Mohamed NS, Choksi US, Mont MA. Current Epidemiology of Revision Total Knee Arthroplasty in the United States. J Arthroplasty [Internet]. 2017 ; 32(9) : 2663-8. Available from : http:// www.ncbi.nlm.nih.gov/pubmed/28456561

27. Pascual-Garrido C, Daley E, Verma NN, Cole BJ. A Comparison of the Outcomes for Cartilage Defects of the Knee Treated With Biologic Resurfacing Versus Focal Metallic Implants. Arthrosc - J Arthrosc Relat Surg [Internet]. 2017 ; 33(2) : 364-73. Available from : http:// dx.doi.org/10.1016/j.arthro.2016.07.010

28. Gomoll AH, Farr J, Gillogly SD, Kercher J, Minas T. Surgical management of articular cartilage defects of the knee. J Bone Joint Surg Am [Internet]. 2010 Oct 20 ; 92(14) : 2470-90. Available from : http:/www.ncbi.nlm. nih.gov/pubmed/20962200

29. Imhoff AB, Feucht MJ, Meidinger G, Schöttle PB, Cotic M. Prospective evaluation of anatomic patellofemoral inlay resurfacing : clinical, radiographic, and sports-related results after 24 months. Knee Surg Sports Traumatol Arthrosc [Internet]. 2015 May ; 23(5) : 1299-307. Available from : http://www.ncbi.nlm.nih.gov/pubmed/24310926

30. Bollars P, Bosquet M, Vandekerckhove B, Hardeman F, Bellemans J. Prosthetic inlay resurfacing for the treatment of focal, full thickness cartilage defects of the femoral condyle: A bridge between biologics and conventional arthroplasty. Knee Surgery, Sport Traumatol. Arthrosc. $2012 ; 20(9)$ : 1753-9.

31. Laursen JO. Treatment of full-thickness cartilage lesions and early OA using large condyle resurfacing prosthesis : UniCAP®. Knee Surgery, Sport Traumatol. Arthrosc. $2016 ; 24(5): 1695-701$.

32. Dhollander AAM, Almqvist KF, Moens K, Vandekerckhove PJ, Verdonk R, Verdonk P, et al. The use of a prosthetic inlay resurfacing as a salvage procedure for a failed cartilage repair. Knee Surgery, Sport Traumatol. Arthrosc. 2015 ; 23(8) : 2208-12.

33. Hobbs H, Merwe W Van Der, Posthumus M. Focal full thickness articular cartilage lesions treated with an articular resurfacing prosthesis in the middle-aged. SA Orthop. J. $2013 ; 12(4)$ : 41-6.

34. Çepni Ş, Veizi E, Tahta M, Uluyardımcı E, Abughalwa MJT, Işık Ç. Focal metallic inlay resurfacing prosthesis in articular cartilage defects: short-term results of 118 patients and 2 different implants. Arch Orthop Trauma Surg [Internet]. 2019 Nov 20 ; Available from : http://www.ncbi. nlm.nih.gov/pubmed/31748883

35. Laursen JO, Lind $\mathbf{M}$. Treatment of full-thickness femoral cartilage lesions using condyle resurfacing prosthesis. Knee Surgery, Sport Traumatol. Arthrosc. 2017 ; 25(3) : 746-51.

36. Laursen JO, Mogensen CB, Skjøt-Arkil H. UniCAP offers a long term treatment for middle-aged patients, who are not revised within the first 9 years. Knee Surgery, Sport Traumatol Arthrosc [Internet]. 2019 ; 27(5) : 16937. Available from : http://dx.doi.org/10.1007/s00167-01905356-y
37. Becher C, Cantiller EB. Focal articular prosthetic resurfacing for the treatment of full-thickness articular cartilage defects in the knee: 12-year follow-up of two cases and review of the literature. Arch. Orthop. Trauma Surg. 2017 ; 137(9) : 1307-17.

38. (2014) RM (RevMan). No Title. Copenhagen Nord Cochrane Centre, 2014 ; The Cochra.

39. Julian P.T. Higgins JT, Jacqueline Chandler, Miranda Cumpston TL, Welch MJP and VA. Cochrane Handbook for Systematic Reviews of Interventions. 2019. 241-284 p.

40. Becher C, Huber R, Thermann H, Tibesku CO, von Skrbensky G. Tibiofemoral contact mechanics with a femoral resurfacing prosthesis and a non-functional meniscus. Clin Biomech [Internet]. 2009; 24(8) : 648-54. Available from: http://dx.doi.org/10.1016/j.clinbiomech. 2009.05.013

41. Manda K, Eriksson A. Modeling of constrained articular cartilage growth in an intact knee with focal knee resurfacing metal implant. Biomech. Model Mechanobiol. $2014 ; 13(3)$ : 599-613.

42. Nagatomo R, Watanabe N, Okubo S, Yokota H, Ikeda H, Yatomi Y. [The comparison study between UniCAP EliA and former kit for measuring the autoantibodies]. Rinsho Byori [Internet]. 2011 Jan ; 59(1) : 31-6. Available from : http://www.ncbi.nlm.nih.gov/pubmed/21404577

43. Waldorff EI, Roessler BJ, Zachos TA, Miller BS, McHugh J, Goldstein SA. Preclinical evaluation of a novel implant for treatment of a full-thickness distal femoral focal cartilage defect. J Arthroplasty [Internet]. 2013 Sep ; 28(8) : 1421-9. Available from : http://www.ncbi.nlm.nih. gov/pubmed/23523501

44. Kirker-Head CA, Van Sickle DC, Ek SW, McCool JC. Safety of, and biological and functional response to, a novel metallic implant for the management of focal full-thickness cartilage defects: Preliminary assessment in an animal model out to 1 year. J Orthop Res [Internet]. 2006 May; 24(5) : 1095-108. Available from : http://www.ncbi.nlm. nih.gov/pubmed/16609973

45. Martinez-Carranza N, Berg HE, Lagerstedt AS, NurmiSandh H, Schupbach P, Ryd L. Fixation of a doublecoated titanium-hydroxyapatite focal knee resurfacing implant: A 12-month study in sheep. Osteoarthr Cartil [Internet]. $2014 ; 22(6)$ : 836-44. Available from : http:// dx.doi.org/10.1016/j.joca.2014.03.019

46. Martinez-Carranza N, Ryd L, Hultenby K, Hedlund H, Nurmi-Sandh H, Lagerstedt AS, et al. Treatment of full thickness focal cartilage lesions with a metallic resurfacing implant in a sheep animal model, 1 year evaluation. Osteoarthr. Cartil. 2016 ; 24(3) : 484-93.

47. Martinez-Carranza N, Berg HE, Hultenby K, NurmiSandh H, Ryd L, Lagerstedt A-S. Focal knee resurfacing and effects of surgical precision on opposing cartilage. A pilot study on 12 sheep. Osteoarthr Cartil [Internet]. 2013 May ; 21(5) : 739-45. Available from : http://www.ncbi. nlm.nih.gov/pubmed/23428602 
48. Salkeld SL, Patron LP, Lien JC, Cook SD, Jones DG. Biological and functional evaluation of a novel pyrolytic carbon implant for the treatment of focal osteochondral defects in the medial femoral condyle: assessment in a canine model. J Orthop Surg Res [Internet]. 2016 Dec 1; 11(1) : 155. Available from : http://www.ncbi.nlm.nih.gov/ pubmed/27906096

49. Brennan SA, Devitt BM, O’Neill CJ, Nicholson P. Focal femoral condyle resurfacing. J. Bone Jt Surg. - Ser B. $2013 ; 95 \mathrm{~B}(3)$ : 301-4.

50. Fuchs A, Eberbach H, Izadpanah K, Bode G, Südkamp NP, Feucht MJ. Focal metallic inlay resurfacing prosthesis for the treatment of localized cartilage defects of the femoral condyles : a systematic review of clinical studies. Knee Surgery, Sport Traumatol Arthrosc [Internet]. 2018 Sep 16; 26(9): 2722-32. Available from: http://link. springer.com/10.1007/s00167-017-4714-4

51. Jeuken RM, Roth AK, Peters RJRW, van Donkelaar CC, Thies JC, van Rhijn LW, et al. Polymers in cartilage defect repair of the knee: Current status and future prospects. Polymers (Basel). 2016 ; 8(6) : 1-30.

52. Malahias MA, Chytas D, Thorey F. The clinical outcome of the different hemiCAP and uniCAP knee implants: A systematic and comprehensive review. Orthop. Rev. (Pavia). 2018 ; 10(2) : 58-64.

53. D'Ambrosi R, Ragone V, Ursino N. What future in the treatment of osteochondral knee defects? Ann. Transl. Med. 2018 ; 6(S2) : S100-S100.

54. Cannon A, Stolley M, Wolf B, Amendola A. Patellofemoral resurfacing arthroplasty : literature review and description of a novel technique. Iowa Orthop. J. 2008 ; 28 : 42-8.

55. Patel A, Haider Z, Anand A, Spicer D. Early results of patellofemoral inlay resurfacing arthroplasty using the HemiCap Wave prosthesis. J Orthop Surg (Hong Kong) [Internet]. 2017 ; 25(1) : 2309499017692705. Available from : http://www.ncbi.nlm.nih.gov/pubmed/28211301

56. Zicaro JP, Yacuzzi C, Astoul Bonorino J, Carbo L, Costa-Paz M. Patellofemoral arthritis treated with resurfacing implant: Clinical outcome and complications at a minimum two-year follow-up. Knee [Internet]. 2017 Dec ; 24(6) : 1485-91. Available from : http://www.ncbi. nlm.nih.gov/pubmed/29021089

57. Feucht MJ, Cotic M, Beitzel K, Baldini JF, Meidinger G, Schöttle PB, et al. A matched-pair comparison of inlay and onlay trochlear designs for patellofemoral arthroplasty: no differences in clinical outcome but less progression of osteoarthritis with inlay designs. Knee Surg
Sports Traumatol Arthrosc [Internet]. 2017 Sep ; 25(9) : 2784-91. Available from: http://www.ncbi.nlm.nih.gov/ pubmed/26231153

58. Gómez-Mont-Landerreche JG, Domínguez-Castro CR, Rosas-Bello CD, Gil-Orbezo FI, Villalobos-Medélez J, Flores-Carrillo A, et al. [Clinical and functional evaluation of patellofemoral resurfacing arthroplasties]. Acta Ortop Mex [Internet]. 33(2) : 107-11. Available from: http:// www.ncbi.nlm.nih.gov/pubmed/31480112

59. Laursen JO. High mid-term revision rate after treatment of large, full-thickness cartilage lesions and $\mathrm{OA}$ in the patellofemoral joint using a large inlay resurfacing prosthesis : HemiCAP-Wave ${ }^{\circledR}$. Knee Surg Sports Traumatol Arthrosc [Internet]. 2017 Dec ; 25(12) : 3856-61. Available from : http://www.ncbi.nlm.nih.gov/pubmed/27714438

60. Beyzadeoglu T, Pehlivanoglu T. Biological Response Following Inlay Arthroplasty of the Knee : Cartilage Flow Over the Implant. Cartilage. 2018 ; 9(2) : 156-60.

61. Miniaci A. UniCAP as an alternative for unicompartmental arthritis. Clin Sports Med [Internet]. 2014 Jan; 33(1) : 57-65. Available from: http://www.ncbi.nlm.nih.gov/ pubmed/24274845

62. Nathwani D, MeNicholas M, Hart A, Miles J, Bobić V. Partial Resurfacing of the Knee with the BioPoly Implant. JBJS Open Access. 2017 ; 2(2) : e0011.

63. Nahas S, Monem M, Li L, Patel A, Parmar H. Ten-Year Average Full Follow-up and Evaluation of a Contoured Focal Resurface Prosthesis (HemiCAP) in Patients in the United Kingdom. J. Knee Surg. 2019 ; 1(212).

64. Miniaci A. UniCAP as an Alternative for Unicompartmental Arthritis. Clin Sports Med [Internet]. 2014 ; 33(1) : 57-65. Available from: http://dx.doi.org/10.1016/j.csm.2013.06. 002

65. Stålman A, Sköldenberg O, Martinez-Carranza N, Roberts D, Högström M, Ryd L. No implant migration and good subjective outcome of a novel customized femoral resurfacing metal implant for focal chondral lesions. Knee Surgery, Sport Traumatol Arthrosc [Internet]. 2018 ; 26(7) : 2196-204. Available from: http://dx.doi.org/10.1007/ s00167-017-4805-2

66. Ingelsrud LH, Terwee CB, Gonçalves RS RR. The association of comorbid conditions with patient. 22(2014) : 179-80.

67. Australian Orthopaedic Association National Joint Replacement Registry. Australian Orthopaedic Association National Joint Replacement Registry (AOANJRR). Hip, knee \& shoulder arthroplasty - Annual Report 2018. 2018 ; 1-444. Available from : www.aoa.org.au 